\title{
Serine/Threonine-Protein Kinase MARK1
}

National Cancer Institute

\section{Source}

National Cancer Institute. Serine/Threonine-Protein Kinase MARK1. NCI Thesaurus. Code C150283.

Serine/threonine-protein kinase MARK1 (795 aa, $~ 89 \mathrm{kDa}$ ) is encoded by the human MARK1 gene. This protein plays a role in the phosphorylation of microtubule-associated proteins (MAPs), which results in microtubule disassembly. 